Actas del Seminario Internacional Destinos Turísticos Inteligentes:

nuevos horizontes en la investigación y gestión del turismo

Universidad de Alicante, 26 y 27 de octubre de 2017

\title{
Evaluación de los Destinos Turísticos Inteligentes: El caso de Málaga ${ }^{1}$
}

María Jesús Perea-Medina

Universidad de Málaga, España

Facultad de Turismo

maria_vva_vva@hotmail.com

Navarro Jurado, Enrique

Universidad de Málaga, España Departamento de Análisis Geográfico Regional

enavarro@uma.es

Guevara Plaza, Antonio

Universidad de Málaga, España Departamento de Lenguajes y Ciencias de la Computación guevara@uma.es

Rossi Jiménez, Carlos

Universidad de Málaga, España Departamento de Lenguajes y Ciencias de la Computación rossi@uma.es

Palabras clave: destino turístico inteligente, evaluación de la inteligencia, indicadores, Málaga

\section{Introducción}

A pesar de la novedad del concepto Destino Turístico Inteligente (DTI) las aportaciones académicas están creciendo notablemente, dada la cantidad de congresos, seminarios, proyectos, etc. que han tratado este tema. El éxito de esta línea de investigación y aplicación tiene motivos diversos: (1) los

1. La presente comunicación se enmarca en el Proyecto de Investigación «Nuevos enfoques para la planificación y gestión del territorio turístico: conceptualización, análisis de experiencias y problemas. Definición de modelos operativos para destinos turísticos inteligentes» (Proyecto CSO2014-59193-R) del Programa Estatal de I+D+I del Ministerio de Economía y Competitividad. 
Actas del Seminario Internacional Destinos Turísticos Inteligentes:

nuevos horizontes en la investigación y gestión del turismo

Universidad de Alicante, 26 y 27 de octubre de 2017

cambios estructurales en el turismo y los destinos justifican la necesidad de nuevos enfoques en la gestión; (2) la evolución demográfica, política, económica y social plantea nuevos retos de gestión de los territorios; (3) las dinámicas del mercado turístico con cambios en los hábitos de consumo; (4) las propuestas de creación de nuevos productos y reestructuración de los tradicionales. Este hecho confirma la exigencia de un nuevo enfoque de la gestión turística/territorial y un nuevo papel para los entes locales (Aguer y Díaz, 2011; Buhalis, 2003), y para todo ello se cuenta con herramientas de mayor alcance, basadas fundamentalmente en la tecnología (Buhalis y Costa, 2006; Walder et al., 2006).

Para avanzar en la propuesta de un DTI se realizan diversas iniciativas. En España el marco general se encuentra en el Plan Nacional e Integral de Turismo (2012-15), las actuaciones que coordina Sociedad Estatal para la Gestión de la Innovación y las Tecnologías Turísticas (Segittur) con sus destinos pilotos, así como la integración de un Subcomité de «Destinos Turísticos» en el Comité de Normalización de Ciudades Inteligentes de AENOR. A escala internacional, destaca el programa chino de Smart Tourism Destination que integra 33 ciudades (Wang et al., 2013).

No son pocos los territorios que empiezan a conceptualizar, identificar un conjunto de buenas prácticas, definir el modelo de destino turístico inteligente operativo e implementar algunas medidas, parciales y en ocasiones descoordinadas, pero que constituyen un avance a tener en cuenta. Es necesario, por tanto, establecer un marco que permita medir la eficacia de las acciones realizadas, que al mismo tiempo servirá para orientar adecuadamente futuras iniciativas.

El objetivo de esta comunicación es evaluar el grado de inteligencia alcanzado por un destino turístico, a través de un conjunto de indicadores. El caso de estudio es el municipio de Málaga.

\section{Métodos}

El método de trabajo se divide en dos partes: (1) la adaptación al caso de estudio del marco conceptual definido por la Comunidad Valenciana (Invat. Tur, 2015), definiendo un sistema de indicadores y las características de los mismos para ser «inteligentes»; (2) evaluación del grado de implementación de dichos indicadores en la gestión del destino a través de entrevistas a responsables técnicos y políticos. 
Actas del Seminario Internacional Destinos Turísticos Inteligentes:

nuevos horizontes en la investigación y gestión del turismo

Universidad de Alicante, 26 y 27 de octubre de 2017

En conjunto se analizan 89 indicadores, divididos en 9 temas en Málaga. Posteriormente se ha incorporado la perspectiva de actores locales realizando entrevistas a los diferentes agentes implicados directa e indirectamente en la gestión turística de la ciudad; la duración total de las entrevistas ha sido de 6,30 horas y se han repartido en diversas áreas municipales como Turismo, Nuevas Tecnologías, Calidad Turística, Accesibilidad y Medio Ambiente. Para cada indicador se requería la misma información (Tipo, Ámbito, Estado, Viabilidad del Indicador, Información, Método de Cálculo, Criterios de Valoración, Acciones de Mejora y Niveles), no obstante, también surgían preguntas y respuestas espontáneas.

\section{Resultados}

Los resultados obtenidos se han dividido en un análisis cuantitativo y otro cualitativo. La primera valoración es que el destino Málaga cumple con los indicadores para valorar su inteligencia turística en un $60,7 \%$, lo que es insuficiente pero supone un avance muy notable. De entre los diferentes temas los más avanzados son los de «Planificación» y "Gobernanza».

Se ha detectado que la "falta de presupuesto», seguida de las «barreras legales» son los justificantes más recurrentes cuando no se ha llegado a medir un indicador o no cumple en su totalidad. Otras razones, habituales en los destinos y en la administraciones públicas, son la «falta de coordinación» y «colaboración interdeparmental».

Destaca el grupo de "Sostenibilidad Territorial», el único grupo donde el $100 \%$ de los indicadores son clave y el $100 \%$ «ya están disponibles», con una gran cantidad de iniciativas y proyectos con coherencia en su conjunto. Sin duda, la puesta en marcha de la Agenda Local 21 municipal ha mejorado los procesos de gestión ambiental, así como la información disponible para la toma de decisiones.

Respecto a los grupos de «Información Turística» y «Marketing Online», los esfuerzos se centran en la promoción del destino Málaga como objetivo número uno, y los resultados son muy positivos, aunque con carencias presupuestarias y de personal para poder alcanzar los objetivos que el momento actual requiere. 
Actas del Seminario Internacional Destinos Turísticos Inteligentes:

nuevos horizontes en la investigación y gestión del turismo

Universidad de Alicante, 26 y 27 de octubre de 2017

\section{Conclusiones}

La primera conclusión de la investigación es clave, Málaga no es todavía un Smart Destination: no cumple un conjunto de indicadores importantes. En la actualidad y en palabras de algunos responsables políticos ser un DTI es un objetivo complejo de alcanzar a día de hoy, porque no se ha contemplado ni hay una partida presupuestaría que cubra los gastos derivados, ni se plantea como parte de la planificación turística ni de otros departamentos del Ayuntamiento. Los avances en innovación y automatización de algunos procesos de gestión del destino se llevan a cabo con diversas actuaciones en los diferentes departamentos, pero no hay una estrategia conjunta para ser un Smart Destination.

Esta investigación puede ser útil para la creación de un Plan DTI y plasmar objetivos y estrategias que lleven a Málaga en una gestión más innovadora, tecnológica y automatizada.

\section{Referencias}

Agencia Valenciana del Turisme. (Invat.tur) (2015). Destinos Turísticos Inteligente. Manual operativo para la configuración de Destinos Turísticos Inteligente. Valencia.

Aguer, O. y Díaz, A. (2011): Landware. Territorio y Tecnología, creadores de valor y generadores de competitividad en turismo, www.landware.com

Buhalis, D. (2003) e-tourism: Information technology for strategic tourism management, Pearson (Financial Times/Prentice-Hall), Londres.

Buhalis, D. y Costa, C. (eds.) (2006): Tourism management dynamics. Trends, management and tools, Elsevier, Oxford.

Walder, B., Weiermaier, K. y Sancho, A. (eds.) (2006): Innovation and Product Development in Tourism. Creating sustainable competitive advantage, Eric Schmidt Verlag, Berlin.

Wang, D., Li, X. y Li, Y. (2013): China's smart tourism destination initiative: A taste of the service-dominant logic, Journal of Destination Marketing and Management, $2(2), 59-61$. 